\title{
Mais mulheres na ciência: questões de conhecimento ${ }^{1}$
}

\author{
Londa Schiebinger ${ }^{2}$
}

SCHIEBINGER, Londa. Mais mulheres na ciência: questões de conhecimento. Apresentação de Maria Margaret Lopes. História, Ciências, Saúde - Manguinhos, Rio de Janeiro, v.15, supl., jun. 2008, p.269-281.

Apresenta considerações, no contexto norte-americano, de teorias e práticas sobre a busca de igualdade para a participação das mulheres nas ciências. Equaciona o desenvolvimento dessas discussões em três níveis de análise: participação das mulheres na ciência; gênero nas culturas da ciência; e gênero nos resultados da ciência. Enfatizando a importância de continuar reunindo exemplos empíricos de como a análise de gênero transformou a teoria e a prática de campos disciplinares como as ciências da vida, primatologia e arqueologia, considera a necessidade de prosseguir na construção de quadros de referência de análise de gênero para outras áreas disciplinares como física e química.

\section{Apresentação}

Os termos conjugados gender and science ${ }^{3}$ completam, em 2008, trinta anos de expressiva vitalidade. As várias revisões historiográficas do campo disciplinar, particularmente nos Estados Unidos, revelam o desdobramento do tema em diversas vertentes, assim como a proliferação de cursos, congressos, livros e artigos científicos a esse respeito. Novas perspectivas de análises, novas autoras e atoras, novos espaços cognitivos surgiram na esteira das mudanças sociais que os movimentos feministas, desde o final dos anos 1960, contribuíram para implantar.

O artigo da conhecida historiadora das ciências norte-americana Londa Schiebinger, que traduzimos sob o título "Mais mulheres na ciência: questões de conhecimento", tem aqui o caráter de documento, de fonte de reflexão sobre o estado da arte e os desafios que os estudos feministas sobre gênero em ciências têm a enfrentar.

No primeiro dos três níveis de análise - necessariamente interconectados - que nos propõe, relativo às agências de fomento e políticas, Londa traz realidades diversas das nossas e nunca abordadas nos sistemas educacionais nacionais. Embora as discussões sobre participação das mulheres nas ciências tenham iniciado, no Brasil, nos anos 1970, até hoje, apesar da ampla disponibilidade de dados, as políticas científicas do país ainda não assimilaram a importância de estabelecer indicadores sobre relações de gênero, que perpassam também o sistema de ciências e tecnologia.

Culturas da ciência (eu prefiro sempre o termo no plural), segundo nível de análise do texto de Londa, indaga os significados de culturas como a das ciências, cujas práticas e valores foram elaborados por profissionais em sua maioria homens, e explora o tema 
através de pesquisas empíricas. Muitas das resistências que indentifico, entre nós, para incorporar nos estudos das ciências as relações de gênero decorrem do não questionamento da universalidade, neutralidade e objetividade das ciências. Sob tais idealizações, evidentemente não há espaço para discussões de raça ou gênero.

No influente feminismo da diferença dos anos 1980, calcado em um suposto 'estilo feminino' de fazer ciências, Londa Schiebinger centra o terceiro nível de sua análise. Para avançar nas análises sobre como as relações de gênero constroem práticas e conteúdos disciplinares, particualrmente em áreas ainda pouco investigadas como a química e a física, é fundamental romper com os estereótipos de gênero, com os estereótipos dos papéis e sentimentos convencionalmente atribuídos a mulheres e homens, que marcam práticas e discursos, mesmo os mais bem-intencionados, também entre nós.

Neste artigo sintético mas fundamental para o tema que aborda, Londa Schiebinger dialoga com temas e práticas que foram e continuam sendo significativos para a construção de perspectivas teóricas. Estabelecer contrapontos, identificar distanciamentos e proximidades são os desafios que o texto nos convida a enfrentar.

Maria Margaret Lopes

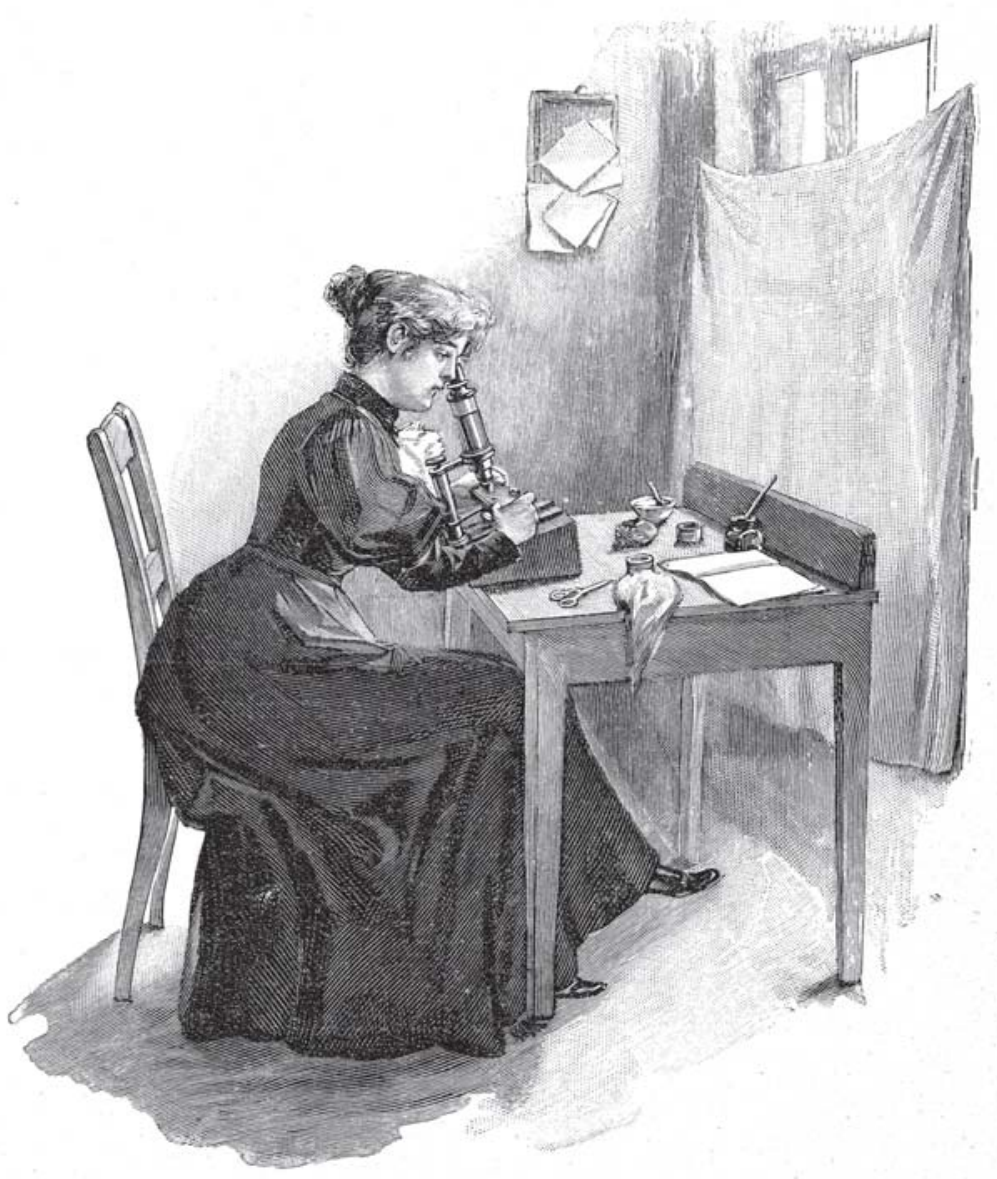


I novações envolvendo mulheres e gênero abalaram os mundos da ciência e da tecnologia nas últimas três décadas. Quem poderia ter previsto, por exemplo, que o cientista-chefe da NASA seria uma mulher (France Córdova, hoje reitora da Universidade de Purdue)? Quem teria pensado que os geneticistas destronariam o modelo do 'gene master' - que conceituava o sexo dos mamíferos como determinado por um único gene master no cromossoma $\mathrm{Y}$ - e colocariam em seu lugar uma versão que enfatiza as interações entre os testículos e os ovários? ${ }^{4}$ Quem poderia imaginar que um joelho artificial seria projetado com 19 aspectos específicos para atender às necessidades singulares do esqueleto e da capacidade de as mulheres suportarem carga? ${ }^{5}$

Nos últimos vinte anos, a situação para as mulheres intelectuais nos Estados Unidos melhorou significativamente. Podemos medir algumas dessas mudanças iconograficamente. Qualquer pessoa que tenha crescido na cultura de consumo dos Estados Unidos compreende o poder das imagens. As imagens projetam mensagens sobre esperanças e sonhos, aparências e comportamentos, e também sobre como deve ser um cientista e em que a ciência consiste. Percebemos algumas mudanças interessantes na maneira pela qual a nossa sociedade imagina como um cientista deva ser. Historicamente, quando estimulados a "desenhar um cientista", 92\% dos estudantes desenhavam homens. No final dos anos 1990, esse percentual caiu para $70 \%$, e cerca de $16 \%$ dos estudantes desenhavam cientistas que eram claramente mulheres e $14 \%$ faziam desenhos ambíguos com relação ao sexo. Um percentual extremamente elevado - 96\% - dos cientistas continuou a ser descrito como caucasianos, a despeito da proeminência dos asiáticos na ciência. ${ }^{6}$

Podemos ver também inovações de gênero no conteúdo da ciência, neste caso no que concerne à compreensão da evolução humana. A maioria de nós cresceu com uma imagem da evolução humana como sendo a 'evolução do homem'. A teoria evolucionista apresentava os homens como os propulsores, ativos e agressivos, da evolução humana.' De acordo com Charles Darwin, somente aquilo que ele denominava de "transmissão igual de caracteres" permitia às mulheres continuarem a evoluir conjuntamente com os homens, que eram os únicos que corporificavam os traços de coragem e inteligência que mantinham os seres humanos em evolução. ${ }^{8}$

Em 1993, uma nova imagem, muito alardeada, foi produzida para corrigir essa representação. Nesse ano, o Museu Americano de História Natural, em Nova York, abriu sua nova exposição sobre a evolução e a biologia humanas retratando a reconstrução dos primeiros humanos a partir de pegadas que datavam de 3,5 milhões de anos atrás, preservadas em cinzas vulcânicas e que tinham sido encontradas nas proximidades de Laetoli, na Tanzânia. Esse diorama confere claramente à mulher um lugar na evolução humana e, embora as conjecturas contidas nessa imagem tenham mudado profundamente desde os anos 1960, o processo ainda se encontra em andamento. Os humanos corporificados pelas pegadas são retratados como um macho robusto erguendo a fêmea sua companheira, menor que ele, estando seu braço posicionado para protegê-la e tranqüilizá-la. Na verdade, porém, não podemos identificar o sexo ou o relacionamento existente entre os dois indivíduos que fizeram essas impressões porque as pegadas não podem ser sexualizadas. As pegadas desses primeiros humanos tanto podem se referir a um grande macho e à sua companheira muito menor quanto a um pai confortando sua filha ou seu filho adolescente, ou ainda a apenas dois amigos fugindo do vulcão. 
O objetivo deste ensaio é analisar a teoria e a prática observadas nos Estados Unidos no sentido de criar igualdade para as mulheres no mundo da ciência. Como quadro de referência, estabeleci três níveis distintos de análise: (1) a participação das mulheres na ciência; (2) o gênero nas culturas da ciência; (3) o gênero nos resultados da ciência. ${ }^{9}$ Embora trate de cada nível separadamente, meu foco recairá no terceiro e explorará, em particular, como a análise de gênero, quando voltada para as ciências, pode afetar profundamente o conhecimento humano. Nós examinaremos como uma compreensão aprofundada do modo pelo qual o gênero funciona na ciência e na sociedade pode abrir novas questões e novos campos para futuras pesquisas e ativar a criatividade em segmentos particulares da ciência.

Embora eu acredite ser útil distinguir esses três níveis analíticos para abordar a questão do maior ingresso de mulheres no mundo da ciência, eles estão intimamente interligados. Creio firmemente, contudo, que as mulheres só virão a se tornar participantes iguais na ciência quando tivermos investigado profundamente o terceiro nível, o nível do conhecimento, e resolvido questões nele presentes.

Quando levamos em consideração que trazer as mulheres para a ciência pode requerer e/ou resultar em mudanças nas teorias e práticas da ciência, devemos nos lembrar que as disciplinas acadêmicas modernas são maneiras arbitrárias de compartimentar conhecimento. Elas são históricas, não são naturais. As disciplinas desenvolveram-se nos últimos duzentos anos, ao longo dos quais as mulheres e minorias sub-representadas foram rigorosamente excluídas da academia..$^{10}$ Precisamos estar abertos à possibilidade de que o conhecimento humano - aquilo que conhecemos, valorizamos e consideramos importante - pode mudar drasticamente quando as mulheres se tornarem participantes plenas na sua produção. A ciência tem a ver com pensamento crítico, exploração e viagens a mundos desconhecidos.

E nós precisamos aproveitar esse momento, quando as universidades de todo o país caminham em direção à interdisciplinaridade de uma maneira sem precedentes. $\mathrm{O}$ conhecimento e os detentores do conhecimento - as instituições acadêmicas - estão sendo reformulados. Agora é tempo de fazer do gênero uma categoria importante de análise em novas configurações disciplinares.

\section{A participação das mulheres na ciência}

O primeiro nível de análise, e o mais cristalino, centra seu foco na crescente participação das mulheres na ciência. Esse nível remete à história e à sociologia do engajamento das mulheres nas instituições científicas. Quem são as grandes mulheres cientistas? Quais são as suas realizações? Quais são as experiências das mulheres nos laboratórios das universidades, das indústrias e do governo?"1

Desde os anos do Sputnik, os Estados Unidos e os países da Europa Ocidental tentaram aumentar a participação de suas populações - tanto de mulheres quanto de homens - na ciência. Nos EUA, isso levou a uma legislação fundadora, que inclui a Lei da Remuneração Igual, de $1963^{12}$, a Lei da Oportunidade Igual de Emprego ${ }^{13}$, e o Título IX, de $1972^{14}$, concebidos para fomentar a igualdade para as mulheres. No início dos anos 1980, a Fundação Nacional da Ciência (National Science Foundation - NSF) procurou aumentar o número 
de mulheres na ciência e na engenharia promovendo um impulso em suas carreiras mediante a alocação de verbas extraordinárias para a pesquisa e para o apoio às suas carreiras. ${ }^{15}$ As Academias Nacionais (a Academia Nacional de Ciência, a Academia Nacional de Engenharia e o Instituto de Medicina) empreenderam programas similares. Fundado em 1991, o Comitê das Academias sobre Mulheres na Ciência e na Engenharia (Committee on Women in Science and Engineering - CWSE) trabalhou em conjunto com o Congresso e com as universidades na definição de uma política voltada para dar assistência às carreiras das mulheres. ${ }^{16}$ Esses tipos de programas visavam, geralmente, aumentar o número de mulheres na ciência mediante a 'preparação das mulheres' - isto é, tornando-as mais competitivas , ampliando o financiamento para as pesquisas empreendidas por mulheres, ensinando-as a negociar melhores salários, ou, de uma forma mais ampla, a como ser bem-sucedidas no mundo masculino.

Um interessante desdobramento observado nesse nível é a tentativa de aplicar o Título IX à ciência. Na primavera de 2005, o Escritório Governamental de Prestação de Contas publicou um relatório elaborado pelos senadores Ron Wyden e Barbara Boxer sobre como o Título IX das emendas para a educação dos Estados Unidos, de 1972, pode ser aproveitado para aumentar o número de mulheres e de membros das minorias na ciência. ${ }^{17}$ Ações sobre esse assunto ainda se encontram em andamento. ${ }^{18}$

\section{Gênero nas culturas da ciência}

Uma cultura é mais do que instituições, regulações legais ou uma série de diplomas e certificados. Ela consiste em suposições e valores não declarados de seus membros. A despeito dos clamores de objetividade e de valor neutralidade, as ciências encerram culturas identificáveis, cujos costumes e hábitos desenvolveram-se ao longo do tempo. Muitos desses costumes desenvolveram-se historicamente não contando com a presença das mulheres e, além disso, como argumentei em outro trabalho ${ }^{19}$, em oposição à participação delas. Esse segundo nível indaga como as culturas da ciência - nas quais o sucesso requer pelo menos algum domínio dos rituais da conformidade cotidiana, dos códigos que governam a linguagem, dos estilos de interações, dos modos de vestir, das hierarquias de valores e práticas - foram elaboradas por profissionais em sua imensa maioria homens. Os programas, nesse nível, visam a 'preparar as instituições'. As bolsas Advance, por exemplo, concedidas atualmente pela Fundação Nacional da Ciência, buscam transformar as culturas na universidade. ${ }^{20}$ Esses esforços variam desde a supressão dos sutis preconceitos de gênero das práticas de contratação, até a reestruturação do equilíbrio da vida e do trabalho acadêmicos mediante o oferecimento da licença-maternidade ou a não exigência do período probatório. ${ }^{21}$

Muito, porém, ainda tem de ser feito nesse nível. Com essa finalidade, o Instituto Clayman de Pesquisa sobre Gênero, da Universidade de Stanford, lançou um importante estudo sobre as carreiras duplas de casais acadêmicos, em 2006. ${ }^{22}$ O fenômeno cada vez mais observado de casais com carreiras duplas representa uma assimetria na cultura profissional que afeta mais as carreiras das mulheres do que a dos homens, uma vez que as mulheres, mais freqüentemente que os homens, têm parceiros profissionais. Entre os casais heterossexuais nos Estados Unidos (ainda não dispomos de estudos equivalentes sobre 
casais do mesmo sexo), as mulheres tendem a praticar a 'hipergamia', vale dizer, tendem a se casar com homens de status superior (ou ao menos não inferior) ao seu. Isso se deve em parte ao fato de que o status social das mulheres foi determinado historicamente pelo casamento, ao passo que o dos homens foi determinado com mais freqüência pela herança ou pelo sucesso profissional. Em conseqüência, hoje em dia, um número muito maior de mulheres profissionais tem como companheiros homens profissionais. Para complicar ainda mais a questão, as profissionais do meio acadêmico tendem a formar casais no interior da mesma disciplina. Por exemplo, embora apenas $6 \%$ dos físicos sejam mulheres, uma parcela muito significativa delas - $43 \%$ - é casada com outros físicos. ${ }^{23}$ Além disso, $25 \%$ do número total de físicas são casadas com cientistas de outras áreas. ${ }^{24}$ Cerca de $70 \%$ das matemáticas - um percentual muito significativo - e $46 \%$ das químicas têm como parceiros homens que atuam nos mesmos campos de atividade. ${ }^{25}$ Embora as universidades tenham começado a alterar as suas práticas de contratação para acomodar alguns casais de dupla carreira, normalmente ser uma das partes, nessa modalidade de casal, torna difícil seguir a lógica de uma carreira e aproveitar as oportunidades quando elas aparecem. ${ }^{26}$

O estudo de Stanford busca compreender as práticas de contratação e de retenção envolvendo casais nas principais universidades norte-americanas voltadas para a pesquisa. Esse estudo culminará em recomendações de políticas que possam auxiliar as universidades no recrutamento e na manutenção de professores renomados, incluindo mulheres, para chefiar o corpo docente e o pessoal administrativo. Reestruturar as práticas da universidade ajudará a transformar o modo pelo qual as universidades fazem negócios e a promover culturas acadêmicas nas quais as mulheres também possam florescer.

\section{O gênero nos resultados da ciência}

Muitas pessoas estão dispostas a admitir que as mulheres não receberam oportunidades adequadas e que as atitudes sociais e as instituições científicas precisam ser reformuladas. Elas também estão cada vez mais propensas a concordar que as mulheres são excluídas de maneiras sutis e muitas vezes invisíveis. Contudo, elas param bruscamente, não chegando a analisar como as práticas e as ideologias calcadas no gênero estruturaram o conhecimento. Será que a questão do gênero na ciência consiste em algo que diz respeito apenas a instituições ou a oportunidades para as mulheres, ou será que ela também impacta o próprio conteúdo dessas disciplinas?

Desde o Iluminismo que a ciência mexe com corações e mentes, ao prometer uma perspectiva 'neutra' e privilegiada, acima e além da briga de foice que caracteriza a vida política. Homens e mulheres responderam de forma semelhante ao chamariz da ciência: "a promessa de tocar o mundo naquilo que ele tem de mais íntimo, um toque que se tornou possível pelo poder do pensamento puro" ${ }^{27} \mathrm{O}$ poder da ciência ocidental - seus métodos, suas técnicas e epistemologias - é celebrado por produzir conhecimento objetivo e universal, transcendendo as restrições culturais. Entretanto, no que diz respeito ao gênero, à raça e a muito mais, a ciência não é um valor neutro. Estudiosos começaram a documentar como as desigualdades de gênero, construídas nas instituições científicas, influenciaram o conhecimento nelas produzido. ${ }^{28}$ 
Discutirei aqui alguns exemplos de como a supressão do preconceito de gênero pode abrir novas perspectivas, novas questões e novas missões à ciência. Mas antes de nos determos nesses exemplos, permitam-me dizer uma palavra sobre o feminismo da diferença nesse aspecto. $\mathrm{O}$ feminismo da diferença - a noção de que as mulheres fazem ciência de uma forma diferente - pode ser especialmente inútil quando aplicado ao conhecimento. $\mathrm{Na}$ década de 1980, boa parte do feminismo da diferença difundia a noção de que as mulheres tinham muito com o que contribuir para a ciência porque, dizia-se, elas sustentam valores diferentes e pensam de forma diferente. ${ }^{29}$ É importante compreender, contudo, que as características de gênero freqüentemente atribuídas às mulheres - a cooperação, o cuidado, o cultivo de um sentimento para com os seres vivos ou o que mais que isso possa ser datam do século XVIII e foram produzidas na tentativa de manter as mulheres fora da ciência e da esfera pública. ${ }^{30}$ Ao romantizar a feminilidade tradicional, o feminismo da diferença pouco faz para superar os estereótipos convencionais de homens e mulheres. As diferenças de gênero historicamente atribuídas às mulheres não podem servir de base epistemológica a novas teorias e práticas nas ciências. Não existem um 'estilo feminino' nem 'maneiras de conhecimento das mulheres' prontos para serem conectados à bancada do laboratório ou na cabeceira da clínica. As mulheres, na condição de fêmeas da espécie, não fazem ciência de um modo diferente; a ciência não deve, necessariamente, ser feita "para mulheres, por mulheres, sobre mulheres". Além do mais, o feminismo da diferença ou a teoria do ponto de vista, como às vezes é chamado, pode tender a excluir os homens da compreensão de como o gênero opera. ${ }^{31}$

Isso não quer dizer que o preconceito de gênero não tenha tido um profundo impacto sobre a ciência: ignorar esses preconceitos é ignorar possíveis fontes de erro no passado e também no futuro da ciência. O que precisamos é desenvolver ferramentas para a análise de gênero. Essas ferramentas devem incluir a reunião de exemplos empíricos de como a análise de gênero altera a teoria ou a prática em subcampos específicos da ciência; desenvolver quadros teóricos para a análise de gênero; desenvolver novas maneiras de abordar essas questões para ciências como a física e a química, nas quais o gênero parece não desempenhar nenhum papel, e demandar treinamento em análise de gênero nos níveis da graduação e da pós-graduação. Deve ser enfatizado que a análise de gênero requer um treinamento rigoroso; não há nenhuma receita que possa simplesmente ser conectada ao planejamento de um projeto de pesquisa. Deve ser igualmente destacado que as ferramentas para a análise de gênero são tão diversas quanto as variantes de feminismo e de ciência. Como com qualquer conjunto de ferramentas, as novas serão adaptadas e as outras descartadas, de acordo com as circunstâncias em mudança. Algumas podem ser facilmente transferidas de ciência para ciência, outras não. O brilho de sua implementação depende, a exemplo dos demais métodos de pesquisa, da criatividade da equipe de pesquisadores. O treinamento na análise de gênero é algo que deve fazer parte da educação dos alunos da graduação e da pós-graduação também nas ciências - para todos. A análise de gênero atua ainda como um outro controle experimental para aumentar o rigor crítico.

Talvez a melhor maneira de se compreender como a análise de gênero funciona é estudar exemplos em que esse tipo de análise abriu novas perspectivas ou visões em áreas específicas. O exemplo mais acabado de como a análise de gênero mudou a ciência vem das ciências 
biomédicas, nas quais testemunhamos uma revolução na pesquisa sobre a saúde das mulheres. Desde os anos 1960, os Estados Unidos vêm assistindo a um ativo movimento em prol da saúde das mulheres; mulheres de todas as classes e com diferentes tipos de experiências demandaram um melhor sistema de saúde. Nos anos 1980, os pesquisadores constataram que muitos estudos médicos financiados pelo governo federal incluíam poucos assuntos relacionados à mulher. ${ }^{32}$ Os críticos verificaram, por exemplo, que um número significativo de estudos médicos, abrangentes e influentes, omitiram completamente as mulheres, destacando-se entre eles o Estudo de Saúde de Médicos sobre Doenças Cardiovasculares e Aspirina, realizado em 1982 com 22.071 médicos homens e nenhuma médica. ${ }^{33}$ Os estudiosos registraram que a pesquisa conduzida primordialmente entre homens durante muitos anos generalizavam as mulheres, muito embora os resultados para as mulheres em termos de doença, diagnóstico, prevenção e tratamento não fossem conhecidos.

O efeito líquido do preconceito de gênero na pesquisa médica e em educação é que as reações adversas às drogas ocorrem com maior freqüência entre as mulheres do que entre os homens. ${ }^{34}$ Por exemplo, anti-histamínicos vendidos livremente e testados inicialmente em homens, podem levar a arritmias cardíacas potencialmente fatais nas mulheres. ${ }^{35}$ É importante apontar que nenhum mecanismo autocorretivo de pesquisa científica entrou em cena para corrigir a abordagem de gênero na pesquisa médica. Parece bastante evidente que estudar drogas em populações não-representativas é apenas má ciência. A correção da situação, nesse caso, requereu intervenção e treinamento conscientes. Significativamente, em 1993 o Congresso norte-americano aprovou uma lei federal solicitando que as mulheres fossem incluídas em experimentos com drogas clínicas, e que o custo não poderia ser usado como justificativa para excluí-las. ${ }^{36}$

Na década de 1990, essa situação começou a melhorar. Os Institutos Nacionais de Saúde (National Institutes of Health - NIH) fundaram o Escritório de Pesquisa em Saúde da Mulher com a dupla missão de aumentar o número de mulheres na profissão médica e reconceituar a pesquisa médica para incluir mulheres. Em 1991, o governo federal anunciou a Iniciativa na Saúde das Mulheres, estudo de doenças exclusiva ou predominantemente femininas. Previsto para quatro anos e contando com um orçamento de 625 milhões de dólares, a Iniciativa é o maior estudo específico até hoje promovido pelos NIH. ${ }^{37}$ Como afirma Bernadine Healy, ex-diretora dos NIH e que supervisionou esse estudo: "Vamos enfrentar isso. A maneira de deslocar cientistas para uma determinada área é financiar essa área". ${ }^{38}$

Acabar com o preconceito de gênero na medicina ajudou a melhorar a saúde e o bemestar das mulheres. Deixar a descoberto o preconceito de gênero, contudo, também pode levar a avanços no conhecimento humano de uma forma mais ampla. Algumas ferramentas da análise de gênero examinam metáforas que geram hipóteses usadas na ciência. Tomemos, por exemplo, a prática extremamente difundida na zoologia de chamar rebanhos - de cavalos, antílopes, elefantes marinhos etc. - de 'haréns'. A suposição é de que um macho poderoso, comportando-se como um sultão, protege suas fêmeas, as quais, por sua vez, reservam seus serviços sexuais apenas para ele. A análise de gênero coloca essas suposições em xeque. Por muito tempo, pensou-se que os cavalos, por exemplo, organizavam-se em 
haréns. O questionamento dessa metáfora consagrada permitiu um novo entendimento científico da procriação e dos comportamentos dos eqüinos. Por exemplo, recentes estudos de DNA dos mustangues, um tipo de cavalo selvagem, revelaram que, em geral, um garanhão é o pai de menos de um terço dos potros de um bando. Se fosse um sultão, não controlou suas fêmeas de forma adequada; as fêmeas parecem ter tido vontade própria e certamente acasalaram-se fora do bando. ${ }^{39}$

Depois da medicina, a biologia foi o campo mais alterado pela análise de gênero. Essas transformações não foram provocadas por políticas das agências financiadoras, mas sim por uma crescente consciência de que a superação do preconceito de gênero poderia melhorar a ciência. Uma vez que a biologia lida com sexo e gênero, e também porque a biologia foi aberta às mulheres (atualmente 45\% dos doutores são mulheres), os biólogos agiram rapidamente para suprimir o evidente preconceito cultural. Além disso, os livros-texto foram revistos, passando a incluir as contribuições das mulheres cientistas e retirando metáforas ultrapassadas e sexistas (como, por exemplo, a do esperma heróico que captura ovos reservados e passivos). ${ }^{40}$

A filósofa da ciência Sarah Richardson conta uma história muito reveladora de como a análise de gênero contribuiu para uma retificação das teorias do determinismo sexual que orientam a pesquisa na biologia reprodutiva. ${ }^{41}$ Tendendo a privilegiar o viés masculino nos anos 1980, os geneticistas promoveram um modelo gene master de determinação do sexo (a noção de que um único gene controla o desenvolvimento de um sistema orgânico completo). ${ }^{42}$ Além disso, consideravam que o cromossoma $\mathrm{Y}$ continha um gene acionador que, em conjunto com os hormônios sexuais, impulsionava o dimorfismo sexual. Nesse modelo, um gene no cromossoma Y inicia a formação dos testículos, e pensava-se que a formação dos testículos determinava o sexo. ${ }^{43}$ Em outras palavras, o cromossoma $\mathrm{Y}$ desencadeava o desenvolvimento nos machos. Pensava-se que a ausência desse acionador determinava o desenvolvimento nas fêmeas.

Richardson registra como o desenvolvimento da análise de gênero nos anos 1990, juntamente com um ativo movimento das mulheres tanto na sociedade quanto na ciência, destronaram o gene master e colocaram em seu lugar um modelo de determinação do sexo que leva em consideração as interações dos testículos e ovários na co-produção do dimorfismo sexual. ${ }^{44}$ Hoje em dia, os biólogos vêem os percursos do macho e da fêmea como altamente interativos. ${ }^{45}$ Prosseguindo, ela salienta um outro ponto importante: embora os geneticistas tenham se tornado, gradualmente, sensíveis às questões de gênero, não deram crédito ao feminismo pelas muitas contribuições que ofereceu. ${ }^{46}$ Muitas vezes, quando o gênero tornase uma entre muitas ferramentas de análise em um programa de pesquisa, suas raízes feministas são ignoradas. Precisamos compreender melhor por que o feminismo, quando ingressa na corrente dominante do pensamento, torna-se rotineiro e não é mais visto como feminista.

Um exemplo final vem do trabalho da paleoantropóloga Lori Hager. Ela investigou como pressupostos não examinados sobre gênero contribuíram para o sexismo, ao sexualizar os fósseis - os aclamados 'achados' para a pesquisa das origens humanas. ${ }^{47}$ Quando vistos acriticamente, os fósseis tendem a nos contar mais sobre as suposições dos pesquisadores dos dias de hoje do que sobre os nossos ancestrais humanos. Trabalhando com esqueletos 
parciais e fragmentados, os paleoantropólogos tendiam, no passado, a sexualizar os espécimes grandes e robustos como machos e os espécimes menores como mulheres. ${ }^{48}$ Essa visão é, em si mesma, tão consolidada que um percentual elevadíssimo - $90 \%$ - dos esqueletos de aborígenes australianos continua sendo sexualizado como de homens - muito acima da proporção esperada para cada sexo, que é de aproximadamente 50\%. ${ }^{49}$ Isso é cientificamente improvável. Hager discutiu como a análise de gênero ajudou os pesquisadores a distinguir melhor que os fósseis, pequenos e grandes, podem representar quer membros femininos ou masculinos de uma espécie altamente dismórfica, quer dizer, indivíduos pertencentes a duas espécies diferentes, uma robusta e outra pequena. ${ }^{50}$

\section{Seguindo em frente}

É mais do que evidente que as divisões sexuais no trabalho físico e intelectual estrutura as instituições, o conhecimento e os objetos do dia-a-dia em nossa própria sociedade, tais como os corações artificiais e os cartões de crédito. É também evidente que a análise de gênero não produziu resultados uniformes nos vários campos da ciência. Embora sejam abundantes os exemplos de como o gênero trouxe novas perspectivas à biomedicina, às ciências da vida, à arqueologia, à primatologia e a tantas outras, exemplos similares não se encontram disponíveis na física ou na química, por exemplo. De um modo geral, as ciências físicas resistiram à análise de gênero. Há várias razões possíveis para que isso aconteça. Em primeiro lugar, observamos que em disciplinas como a biomedicina e a biologia, que contam com um bom número de mulheres profissionais, houve mais progresso nas questões de conhecimento. Mas o que veio primeiro: a abertura da disciplina a novas visões intelectuais ou o maior número de mulheres nessas disciplinas? Não sabemos. A verdade é que o número de pessoas treinadas, quer na física quer na química, em estudos de gênero é extremamente pequeno e essa situação deve ser remediada. Em segundo lugar, a falta de interesse pela análise de gênero nas ciências físicas pode também ser causada pelo fato de os objetos e os processos das ciências físicas serem menos obviamente calcados no gênero, se é que são de algum modo. A inexistência de dimensões de gênero na física ou na química, no entanto, é hoje simplesmente uma hipótese bem-formulada. Precisamos partir para a pesquisa.

Uma vez que realizamos algum progresso útil no desenvolvimento da análise de gênero para as ciências naturais, como podemos colocar esse tipo de análise no trabalho do dia-adia da ciência? Temos dois passos a dar. Primeiramente, precisamos treinar os estudantes, tanto de graduação quanto de pós-graduação, juntamente com os professores, a integrar a análise de gênero em suas pesquisas. Embora muitas pessoas concordem que um estudante precisa aprender biologia molecular ou física de partículas a fim de ganhar excelência nesses campos, muitos acreditam que seja possível adquirir uma compreensão de gênero apenas com a experiência. Na verdade, a compreensão de gênero, como em qualquer outro campo de investimento intelectual, requer pesquisa, desenvolvimento e treinamento. Os programas dos NIH que descrevi anteriormente funcionaram, entre outros motivos, porque um corpo consistente de pesquisa de gênero sobre esses assuntos estava disponível em um bom número de instituições de ponta em todo o país. Novas possibilidades também são 
vislumbradas no horizonte. Se estamos treinando professores universitários e estudantes de pós-graduação sobre os preconceitos de gênero em culturas científicas, por meio de programas como o extremamente bem-sucedido Estratégias e Táticas Para Recrutar e Estimular a Diversidade e a Excelência (Strategies Diversity and Excellence - Stride), da Universidade de Michigan, adicionar uma dimensão de conhecimento é algo relativamente fácil. ${ }^{51}$

Em segundo lugar, e é aí que a política entra em cena, precisamos fazer com que a Fundação Nacional de Ciência reivindique que a ciência financiada com recursos federais integre a análise de gênero no planejamento da pesquisa, quando for o caso. A NSF está ficando para trás em relação a outras agências federais e internacionais, sob esse aspecto. Nas NIH, como observamos acima, o Escritório de Pesquisa Sobre a Saúde da Mulher promove uma avaliação adequada das diferenças sexuais na pesquisa médica. ${ }^{52}$ Além disso, na Comissão Européia, a Diretoria Geral para Pesquisa requer não apenas que o desenho do projeto contemple "de forma sistemática se, e em que sentido, sexo e gênero são relevantes nos objetivos e metodologia de projetos", como também que os requisitos da pesquisa devam atender às necessidades das mulheres tanto quanto às necessidades dos homens, $\mathrm{e}$ que a participação das mulheres em pesquisa deve ser encorajada tanto como cientistas/ tecnólogas quanto no interior do processo de avaliação, consulta e implementação. ${ }^{53}$ Os formuladores de políticas devem direcionar a NSF para essa posição e demandar que a ciência e a engenharia financiadas com recursos federais passem a integrar a análise de gênero no planejamento da pesquisa, onde for adequado. Alguns países europeus, como a Holanda e a Suécia, fizeram do aumento do número de mulheres, em conjunto com a integração da análise de gênero no planejamento da pesquisa, parte de suas políticas científicas nacionais. Contudo, mesmo onde isso é o caso, é necessário mais treinamento em como incorporar a análise de gênero à pesquisa científica. Numa recente visita à Suécia, verifiquei que, embora essas políticas estejam em execução, poucos pesquisadores sabem exatamente o que fazer.

À guisa de conclusão, reitero que muito trabalho ainda está para ser feito. Uma das muitas tarefas de mais simples execução é continuar a reunir exemplos empíricos de como a análise de gênero transformou a teoria e a prática em subcampos específicos da ciência. ${ }^{54}$ Precisamos igualmente continuar a desenvolver quadros de referência de análise de gênero que abordem essas questões para ciências como a física e a química, nas quais o gênero parece não desempenhar nenhum papel no conhecimento. Permitam-me salientar, uma vez mais, que esse trabalho é crucial para os nossos esforços em recrutar e manter as mulheres - não solucionaremos esse problema até que resolvamos o problema do conhecimento. É fascinante que ciências como a biomedicina, a primatologia, a arqueologia e a biologia, nas quais a análise de gênero floresceu, tenham um número relativamente elevado de mulheres. Nesses campos, e em muitos campos na área das ciências humanas, o uso da análise de gênero adicionou brilho e criatividade através da formulação de novas questões e da abertura de novas áreas para a pesquisa. Que preço teremos de pagar se ignorarmos essas oportunidades? 


\section{NOTAS}

${ }^{1}$ Esse ensaio foi publicado no Harvard Journal of Law and Gender (Cambridge, v.31, n. 2, p.365-378, 2007), sob o título "Getting more women into science: knowledge issues". Tradução, Sergio T.N. Lamarão.

${ }^{2}$ Professora de história da ciência na Universidade de Stanford e diretora do Instituto Michelle R. Clayman de Pesquisa Sobre Gênero, na mesma universidade.

${ }^{3}$ Evelyn Fox-Keller, Gender and science. Psychoanalysis and Contemporary Thought,1, 1978, p.409-433

${ }^{4}$ Sarah S. Richardson, When gender criticism becomes standard scientific practice: the case of sex determination genetics, in Gendered Innovations in Science and Engineering (Londa Schiebinger ed., 2008).

${ }^{5}$ Barnaby J. Feder, Women get knees to call their own, New York Times, 11 de maio de 2006, C3.

${ }^{6}$ Idem.

${ }^{7}$ Ver Man the hunter (Richard B. Lee \& Irven DeVore ed., 1968).

${ }^{8}$ Linda Marie Fedigan, The changing role of women in models of human evolution, 15 Annual Revue of Anthropology 25, p.29-33 (1986); ver também Sarah Blaffer Hrdy, The woman that never evolved (1999) (que descreve como o darwinismo social foi usado para explicar e justificar as desigualdades sociais entre homens e mulheres). Para críticas anteriores feitas a Darwin, ver Hedwig Dohm, Women's nature and privilege (tradução de Constance Campbell, Hyperion 1976) (1896); Eliza Burt Gamble, Evolution of woman: an inquiry into the dogma of her inferiority to men (Hyperion 1976) (1894); Antoinette Brown Blackwell, The sexes throughout nature (Hyperion 1976) (1875).

${ }^{9}$ Ver Londa Schiebinger, Has feminism changed science? (1999). Edição brasileira: O feminismo mudou a ciência? Trad. Raul Fiker. Bauru: EDUSC, 2001.

${ }^{10}$ Ver Londa Schiebinger, The mind has no sex?: women in the origins of modern science (1989).

${ }^{11}$ Ver Margaret W. Rossiter, Women scientists in America: before affirmative action, 1940-1972 (1995) (enfocando as posições das mulheres nos laboratórios científicos em meados do século XX); The outer circle: women in the scientific community (Harriet Zuckerman et. al. eds., 1991) (que discute a pesquisa moderna com mulheres na ciência); Margaret W. Rossiter, Women scientists in America: a struggles and strategies to 1940 (1982) (que discute o início da presença das mulheres nos laboratórios científicos).

${ }^{12}$ Lei da Remuneração Igual (Equal Pay Act), de 1963, § 1, 29 U.S.C. § 201 (2000).

${ }^{13}$ Lei da Oportunidade Igual de Emprego (Equal Employment Opportunity Act), de 1972, § 1, 42 U.S.C. $\S 2000$ e (2000).

14 Título IX das Emendas em Educação, de 1972, § 1, 20 U.S.C. § 1681 (2000).

${ }^{15}$ Sue V. Rosser, Building two-way streets to implement policies that work for gender and science, in Gendered innovations in science and engineering, supra nota 4.

${ }^{16}$ France A. Córdova, Projects of the national academies on women in science and engineering, in Gendered inovations in science and engineering, supra nota 4.

${ }^{17}$ U.S. Government Accountability Office, Gender issues: women's participation in the sciences has increased, but agencies need to do more to ensure compliance with Title IX, GAO Report No. GAO-04-639 (2004), disponível em http://www.gao.gov/new.items/d04639.pdf.

${ }^{18}$ Ver, por exemplo, Instituto Michelle R. Clayman de Pesquisa sobre Gênero, Universidade de Stanford, Making use of Title IX: women in sciences, engineering, technology, and mathematics (2006), disponível em http://www.stanford.edu/group/gender/ResearchProgramas/TitleIX.html.

${ }^{19}$ Ver Schiebinger, supra nota 10.

${ }^{20}$ National Science Foundation, Advance: Increasing the Participation and Advancement of Womwn in Academic Science and Engineering Careers (2005) , disponível em http://www.nsf.gov/pubs/2005/nsf05584/ nsf05584.htm. A sinopse do programa, que está disponível no website, afirma: "Os Prêmios de Transformação Institucional apóiam a transformação acadêmica institucional visando à promoção de uma maior participação e do avanço das mulheres cientistas e engenheiras na academia. Esses prêmios apóiam programas inovadores e abrangentes que mudem as instituições de forma ampla".

${ }^{21}$ Ver Schiebinger, Has feminism changed science?, supra nota 9; para comentários sobre a maximização do potencial das mulheres nas academias nacionais de Ciência e Engenharia, ver Beyond bias and barriers: fulfilling the potential of women in academic science and engineering (2006); e Virginia Valian, Why so slow?: the advancement of women (1998). 
22 Ver Instituto Michelle R. Clayman de Pesquisa sobre Gênero, Universidade de Stanford, Dual career academic couples (publicação prevista para 2008), descrição disponível em http://www.stanford.edu/ group/gênero.

${ }^{23}$ Pamela Hawkins Blondin, American Physical Society, 1990 survey of the membership of the American Physical Society 19, 23-24 (1990).

${ }^{24}$ Idem.

${ }^{25}$ Instituto Michelle R. Clayman de Pesquisa sobre Gênero, Universidade de Stanford, Dual-career academic couple study, 2006/07 pesquisa efetuada em 13 universidades de pesquisa dos Estados Unidos; resultados não publicados.

${ }^{26}$ Ver Lisa Wolf-Wendel et. al., The two-body problem: dual-career-couple hiring policies in higher education (2003); Laurie McNeil \& Marc Sher, Dual-science-career-couples: survey results (1998), disponível em http://www.physics.wm.edu/ sher/survey.pdf.

${ }^{27}$ Evelyn Fox-Keller, Secrets of life, secrets of death: essays on language, gender and science 78 (2002).

${ }^{28}$ Ver, por exemplo, Engendering archaeology: women and prehistory (Joan Gero \& Margaret W. Conkey eds., 1991); Londa Schiebinger, Nature's body: gender in the making of modern science (2004); Schiebinger, supra nota 9; Bonnie Spanier, Impartial science: gender ideology in molecular biology (1995); Women in human evolution (Lori Hager ed., 1997).

${ }^{29}$ Mary Belenky et al., Women's ways of knowing: the development of self, voice, and mind (1986); Knowledgment, difference, and power: essays inspired by women's ways of knowing (Nancy Goldberger et al. eds., 1996).

${ }^{30}$ Ver Schiebinger, supra nota 10, p.214-264.

${ }^{31}$ Ver Schiebinger, supra nota 9, p.4-8.

${ }^{32}$ Ver Womens's health: complexities and differences (Sheryl Ruzek et. al. eds., 1997).

${ }^{33}$ Sue V. Rosser, Women's health: Missing from U.S. Medicine 6 (1994). Estudos recentes demonstraram que embora a aspirina tenha diminuído de forma significativa o risco de ataque cardíaco entre os homens, o mesmo não aconteceu com as mulheres. Eliot Marshall, From death to deluge, 308 (5728) Science 1570 (2005).

${ }^{34}$ Anna Mastroianni et al., Institute of Medicine, Women and health research: ethical and legal issues of including women in clinical studies, v. II, 37 (1994).

${ }^{35}$ Jocelyn Kaiser, Gender in the pharmacy: does it matter? 308 (5728) Science 1572 (2005).

${ }^{36}$ Lesley Primmer, Women's health research: Congressional action and legislative gains: 1990-1994, in Women's health research: a medical and policy primer 314 (Florence Haseltine \& Beverly Jacobson ed., 1997).

${ }^{37}$ Primmer, supra nota 36, p.301, 309-310.

${ }^{38}$ Trisha Gura, Estrogen: key player in heart disease among women 269 Science 771, 773 (1995).

${ }^{39}$ Schiebinger, Has feminism changed science?, supra nota 9, p.149.

${ }^{40}$ Ver Emily Martin, The egg and the sperm: how science has constructed a romance based on stereotypical male-female roles, 16 Signs: Journal of Women in Culture and Society 485 (1991).

${ }^{41}$ Ver Richardson, supra nota 4.

${ }^{42}$ Idem.

${ }^{43}$ Idem.

${ }^{44}$ Idem.

${ }^{45}$ Idem.

${ }^{46}$ Idem.

${ }^{47}$ Lori D. Hager, Sex matters: letting skeletons tell the story, in Gendered innovations in science and engineering, supra nota 4.

${ }^{48}$ Idem.

${ }^{49}$ Idem. 
${ }^{50}$ Idem.

${ }^{51}$ Abigail J. Stewart et al., Recruiting women faculty in science and engineering: preliminary evaluation of one intervention model, 10 Journal of Women and Minorities in Science and Engineering 361 (2004).

52 Office for Research on Women's Health, 2 Agenda for Research on Women's Health for the 21st Century 205-11 (1999), disponível em http://orwh.od.nih.gov/research/Agenda_Book_2.pdf.

${ }^{53}$ European Commission, Annex 4: Integrating the gender dimension in FP6 Projects, in Guide for proposers, research and innovation: structuring the European research (2006). A exigência de que a análise de gênero fosse inserida no planejamento de pesquisa foi retirada na $7^{\mathrm{a}}$ reunião da União Européia. Ministério da Educação e Pesquisa da Alemanha/ Conferência da Comissão de Pesquisa da União Européia, Berlim, abril de 2007.

${ }^{54}$ Ver também Schiebinger, supra nota 9. 